\title{
Exercise-induced bronchoconstriction by ethnicity and presence of asthma in British nine year olds
}

\author{
Caroline O H Jones, Sameena Qureshi, Roberto J Rona, Susan Chinn
}

\begin{abstract}
Background - The prevalence of exerciseinduced bronchoconstriction among British children by ethnicity has not been studied.

Methods - Peak expiratory flow rate (PEFR) was measured before and after an exercise challenge test using a cycle ergometer in 593 nine year olds from Scottish and inner city English schools. Logistic regression analysis was carried out to assess the association between changes in PEFR with exercise by reported asthma, ethnicity, and sex.

Results - The probability of exercise-induced bronchoconstriction was greater among the asthmatics than in either the children without asthma attacks or wheeze, or in the children with only wheeze $(p<0.01)$. Asian children were 3.6 times more likely to have exercise-induced bronchoconstriction than white inner city children, and also were more likely to have exercise-induced bronchoconstriction than those from the other ethnic groups (p <0.01).

Conclusion - Exercise challenge can assess the prevalence of asthma in the community and detect under-reporting of asthma in ethnic minorities.

(Thorax 1996;51:1134-1136)
\end{abstract}

Keywords: exercise-induced bronchoconstriction, asthma, ethnicity, children.

With the exception of the data provided by Burr and his colleagues on Welsh children, ${ }^{1}$ little information is available on the prevalence of exercise-induced bronchoconstriction in British children. Data are not available on

Table 1 Prevalence of asthma attacks and wheeze among the children

\begin{tabular}{lrlcl}
\hline Ethnic origin* & Total & $\begin{array}{l}\text { \% with } \\
\text { asthma }\end{array}$ & $\begin{array}{l}\text { \% with wheeze } \\
\text { but no asthma }\end{array}$ & $\begin{array}{l}\text { \% with no asthma, } \\
\text { no wheeze }\end{array}$ \\
\hline White inner city & 157 & 7.6 & 8.3 & 84.1 \\
Afro-Caribbean & 59 & 8.5 & 15.3 & 76.3 \\
Asian & 147 & 2.7 & 4.1 & 93.2 \\
Other & 61 & 6.6 & 13.1 & 80.3 \\
Scottish & 193 & 4.7 & 6.2 & 89.1 \\
Total & 617 & 5.5 & 7.8 & 86.6 \\
\hline
\end{tabular}

* Ethnic origin of one child was unknown. the prevalence of exercise-induced bronchoconstriction in children of different ethnic groups, nor on the relationship between parents' reports of asthma attacks or wheezing and exercise-induced bronchoconstriction.

In 1992 the scope of the National Study of Health and Growth (NSHG) was increased to include measures of cardiovascular fitness in nine year olds ${ }^{2}$ and the peak expiratory flow rate (PEFR) of the participating children was measured before and after an exercise test. These data allowed us to assess the prevalence of exercise-induced bronchoconstriction according to the prevalence of reported asthma and ethnic origin.

\section{Methods}

Details of the sample selection for the NSHG have been published elsewhere. ${ }^{3}$ Briefly, in even years the survey covers two samples, an English representative sample and half of a Scottish representative sample, while in odd years the survey is undertaken in English inner city areas, half of which have a high proportion of AfroCaribbeans or children originating from the Indian subcontinent (Asians), as well as in the other half of the Scottish representative sample. The data reported in this paper were collected in 1993, which was a year in which English inner cities and half of the Scottish sample were studied. The Scottish sample only included white children from rural and urban geographical areas. The exercise testing was carried out on children who were between 8.5 and 9.5 years old. As time for exercise testing was limited to one week in each study area, not all eligible children who had parental consent could be tested for exercise-induced bronchoconstriction, so testing was started either from the beginning or the end of the alphabetical class list by random allocation. ${ }^{2}$ PEFR measurements were made using a miniWright peak expiratory flow meter. After demonstrating the measurement to each child, PEFR was measured three times and the mean of the three values taken as the PEFR for that child. PEFR was measured before exercise and at five and 10 minutes after the completion of exercise. The exercise test consisted of six minutes of continuous cycling on a cycle ergo- 
Table 2 Prevalence, odds ratio (OR) and 95\% confidence interval (95\% CI) for exercise-induced bronchoconstriction (EIB) according to ethnic group and asthma status, each adjusted for sex, height, and the other variable

\begin{tabular}{|c|c|c|c|c|}
\hline \multirow[t]{2}{*}{ Variable } & \multicolumn{2}{|c|}{ EIB prevalence } & \multicolumn{2}{|l|}{$E I B$} \\
\hline & No & No (\%) & OR $(95 \% C I)$ & $p$ \\
\hline $\begin{array}{l}\text { Ethnic group } \\
\text { White inner city } \\
\text { Afro-Caribbean } \\
\text { Asian } \\
\text { Other } \\
\text { Scottish }\end{array}$ & $\begin{array}{r}155 \\
55 \\
138 \\
54 \\
191\end{array}$ & $\begin{aligned} & 7(4.5) \\
& 5(9.1) \\
& 17(12.3) \\
& 4(7.4) \\
& 5(2.6)\end{aligned}$ & $\begin{array}{l}1.00 \\
1.75(0.50 \text { to } 6.09) \\
3.59(1.39 \text { to } 9.27) \\
1.79(0.49 \text { to } 6.58) \\
0.31(0.18 \text { to } 4.70)\end{array}$ & $<0.01$ \\
\hline $\begin{array}{l}\text { Asthma status } \\
\text { Asthma attacks } \\
\text { Wheeze, no asthma } \\
\text { No asthma, no wheeze }\end{array}$ & $\begin{array}{r}31 \\
46 \\
516\end{array}$ & $\begin{array}{r}3(19.4) \\
1(2.17) \\
31(6.00)\end{array}$ & $\begin{array}{l}1.00 \\
0.07 \text { (0.00 to } 0.63) \\
0.20(0.07 \text { to } 0.57)\end{array}$ & $<0.01$ \\
\hline
\end{tabular}

meter reaching $85 \%$ of maximum heart rate. ${ }^{2}$ In common with other studies, if a child suffered sufficient bronchoconstriction within 10 minutes of the completion of exercise to produce a decrease in PEFR exceeding 15\%, then the child was categorised as having exercise-induced bronchoconstriction. ${ }^{14}$

Ethnicity was classified as shown in table $1 .^{3}$ In a self-administered questionnaire parents were asked whether the child had suffered from asthma attacks in the past 12 months and whether his or her chest ever sounded wheezy or whistling. Each child was assigned to one of three symptom groups: (1) children reported as having asthma attacks in the previous 12 months (asthma group), (2) children reported as not having asthma attacks but having wheeze (wheeze but no asthma), and (3) those reported as not having asthma attacks or wheeze (no asthma or wheeze).

Logistic regression analysis was performed to assess to what extent children with a decrease of at least $15 \%$ in the PEFR five or 10 minutes after exercise could be predicted from ethnic background and parental reporting of asthma and wheeze.

\section{Results}

Of the 1137 children with data on asthma, $90(7.9 \%)$ were reported to have had asthma attacks of whom $55(10 \%)$ were boys and 35 $(6 \%)$ were girls. Six hundred and forty six children undertook the exercise testing, but 28 children (20 in the asthma group and eight with wheeze but no asthma) were excluded because of use of an inhaler. Of the 28 children using an inhaler 15 were white, six Afro-Caribbean, three Asian, three other, and one unknown. The prevalence of reported asthma among the questionnaire respondents and those who had a pre-exercise PEFR was $8 \%$, which was reduced to $5 \%$ after excluding those who used an inhaler. Among those who undertook the exercise test children of Asian origin and those in the Scottish sample had the lowest percentage of reported asthma and wheeze but not asthma (table 1).

Seventeen children, three of whom (17\%) were asthmatic, were unable to complete the exercise test. Eight children did not have a PEFR reading 10 minutes after exercise. Among the remaining 593 children those with asthma had the lowest ratio of post-exercise to pre-exercise PEFR (98.6\%), wheezers without asthma attacks were intermediate $(103.0 \%)$, and the non-asthmatic non-wheezers $(105.8 \%)$ had the highest ratio $(\mathrm{p}<0.01)$.

The prevalence of exercise-induced bronchoconstriction was highest among the reported asthmatics (19\%), intermediate in the non-asthmatic non-wheezing group (6\%), and lowest $(2 \%)$ among the 46 wheezers with no asthma attacks (table 2). These differences were significant after adjustment for ethnic background, height, and sex $(p<0.01)$. The prevalence of exercise-induced bronchoconstriction was greatest among the Asian children $(12 \%)$ and least among the white Scottish children $(3 \%)$. The difference between ethnic groups was significant $(p<0.01)$ and the odds ratio for exercise-induced bronchoconstriction was 3.6 in Asian children compared with white inner city children. These results were virtually unchanged on adjusting for initial PEFR. Seventeen Asian children developed exerciseinduced bronchoconstriction whereas only 10 were reported as having asthma attacks or wheeze by their parents.

\section{Discussion}

The prevalence of exercise-induced bronchoconstriction in those who were reported as being non-asthmatic by their parents (including both wheezers and non-wheezers) was $4.4 \%$, slightly less than that found in other studies. ${ }^{56}$ The prevalence of exercise-induced bronchoconstriction in asthmatics undertaking the test without inhaler use was lower (19\%) than the $20-63 \%$ for non-selected asthmatics reported elsewhere. ${ }^{4-6}$

The prevalence of exercise-induced bronchoconstriction among asthmatics may have been reduced by the exclusion from the analysis of three asthmatic children who did not finish the cycle ergometer test and 20 who used an inhaler on the morning of the test. If all those excluded had exercise-induced bronchoconstriction, the percentage would have increased from $19 \%$ to $48 \%$. With a less extreme assumption, say $60 \%$ of those excluded had exercise-induced bronchoconstriction, the prevalence would have been $31 \%$. This suggests that the reporting of asthma by parents correlates to some extent with a child's bronchial response to exercise despite the known fact that exercise testing using a cycle ergometer is a less potent trigger for exercise-induced bronchoconstriction than free or treadmill running. ${ }^{7}$

Children of Asian origin were found to have a considerably higher prevalence of exerciseinduced bronchoconstriction (12\%) than those from any of the other ethnic groups (3-9\%). This is interesting because, with the exception of Asian children, there was a correspondence between the reporting of asthma attacks by parents (table 1) and exercise-induced bronchoconstriction in their children (table 2). The perception of asthma by Asian parents is also contradicted by the larger number of casualty and hospital admissions among Asians than among white British subjects. ${ }^{89} \mathrm{~A}$ possible explanation for our findings is that some Asian 
parents in our study did not understand the terms "wheeze" and "asthma" despite the use of a bilingual questionnaire.

This study shows, in an unselected sample, that a high percentage of children with asthma attacks have exercise-induced bronchoconstriction and that Asian parents may underreport asthma and wheeze in comparison with other ethnic groups in Britain.

We thank all those who helped with this study. The National Study of Health and Growth is supported by the Department of Health and the Scottish Home and Health Department.

1 Burr ML, Butland BK, King S, Vaughan-Williams E. Changes in asthma prevalence: two surveys 15 years apart. Arch Dis Child 1989;64:1452-6.

2 Kikuchi S, Rona R, Chinn S. Physical fitness of 9 year olds in England: related factors. $\mathcal{F}$ Epidemiol Community Health 1995;49:180-5.

3 Rona RJ, Chinn S. National Study of Health and Growth: social and biological factors associated with height of children from ethnic groups living in England. Ann Hum Biol 1986;13:453-71.

4 Bransford RP, McNutt GM, Fink JN. Exercise-induced asthma in an adolescent gym class population. Int Arch Allergy Appl Immunol 1991;94:272-4

5 Bierman CW, Kawabori I, Pierson WE. Incidence of exerciseinduced asthma in children. Pediatrics 1975;56(Suppl):84750.

6 Backer V, Ulrik CS. Bronchial responsiveness to exercise in a random sample of 494 children and adolescents from Copenhagen. Clin Exp Allergy 1992;22:741-7.

7 Eggleston PA. The cycle ergometer as a system for studying exercise-induced asthma. Pediatrics 1975;56(Suppl):899902

8 Parajasingam CD, Sittampalam L, Damani P, Pattemore PK, Holgate ST. Comparison of the prevalence of asthma among Asian and European children in Southampton Thorax 1992;47:529-32.

9 Ayres JG. Acute asthma in Asian patients: hospital admissions and duration of stay in a district with a high immigrant population. Brf Dis Chest 1986;80:242-8. 